This is an author produced version of a paper published in Studies in Higher Education. This paper has been peer-reviewed but does not include the final publisher proof-corrections or journal pagination.

Citation for the published paper:

Ek, Anne-Charlotte; Ideland, Malin; Jönsson, Sandra; Malmberg, Claes. (2013). The tension between marketisation and academisation in higher education. Studies in Higher Education, vol. 38, issue 9, p. null

URL: https://doi.org/10.1080/03075079.2011.619656

Publisher: Taylor \& Francis

This document has been downloaded from MUEP (https://muep.mah.se) / DIVA (https://mau.diva-portal.org). 


\section{Higher education in the field of tension between marketisation and academisation}

\section{Anne-Charlotte Ek, Malin Ideland, Sandra Jönsson and Claes Malmberg}

The contemporary change of higher education in Sweden is characterised by two different educational discourses, here described as marketisation and academisation. Demands for market adjustment, in conjunction with requirements on scientificity, have created tensions on the level of society, and between and within institutional cultures. This article investigates, through interviews, how tensions between marketisation and academisation are handled by prefects at traditional discipline-oriented and at professional-oriented departments. Prefects at discipline-oriented departments experience marketization as a threat to the university trademark through challenging academic autonomy. The latter prefects experiences academisation as the main struggle as it shift focus from practical skills towards academic meritocracy. The analysis offers that it is not possible to talk about changes in the new academy, as if we assume that conditions do not differ substantially across the university. The authors mean that changes can be countered by culturally sensitive strategies rather than imagine that "one size fits all".

Over the past decades, higher education in Sweden, as in most other European countries, has undergone a series of political reforms. The Bologna process has meant that programmes have become goal-oriented, with ensuing requirements to document that goals are met. This also means that courses are evaluated centrally by the Swedish National Agency for Higher Education. Moreover, the Bologna reform has increased requirements that education lead to employability. In addition, increasing demands are placed on the "scientificity" in education, and the requirement that instruction be linked to research, while also collaborating with society at large. Higher education is supposed to enhance its scientific expertise, while at the same time reinforcing its ties to industry. We will therefore argue that the Swedish higher education in the 2000s is characterised by two different educational discourses, here described as marketisation and academisation.

The scientific community has criticised that higher education is increasingly subject to economic steering, since the allocation of resources has become a function of student performance, as well as research achievements. This debate has mainly been put forward by the proponents of a more traditional university: philosophers, historians, sociologists, and others. Many of the previous studies on these issues have concerned a macro level, that is, changes in educational policy in relation to social discourses, which often goes under the notion of New Public Management. The present study will instead examine how these changes are expressed at a micro level (i.e., department level). Contemporary demands for market adjustment, in conjunction with requirements that higher education be closely linked 
to research, have created tensions on the level of society, but also between and within different institutional cultures. These tensions are dealt with concretely at the individual department itself - in particular by holders of positions with leadership functions. The study aims to describe and discuss how changes in the conditions affecting higher education are expressed, and are dealt with at the level of prefects. More specifically, the present investigation concerns how tensions between marketisation and academisation are handled by prefects within various institutional cultures.

\section{Changes in higher education}

As outlined above, the research field "changes in higher education" has largely been researched from a critical perspective on the impact of neoliberal market ideas on universities. In the following section, we will give a picture of what this marketisation involves, and how it has been described in previous studies. We will then proceed to describe the second discourse of change, academisation, and take a look at how it has been treated in the literature.

\section{Marketisation}

The marketisation of higher education is often described as changes in a previously relatively autonomous academic organisation, in the direction of a system based on business ideals. The new ideals govern the management of the organisation and the way results are measured; private players are invited to take care of parts of the activities. Above all, the changes mean that business ideals in organising, managing and measuring the results of the activity will increasingly influence the organisation (Ball 2004). Benner and Sandström (2000) argue that political and business interests have been integrated into the research conducted at traditional universities, and are now challenging their norms.

The changes also involve more evaluative and regulatory control (Kolsaker 2008). External examiners evaluate and rank universities 'results, using quantifiable indicators. This means a shift away from the traditional universities' rules-based meritocracy (Olssen, 2002).

Harris (2005) points to a partially altered self-image among academics, as a result of the changing conditions, where traditional notions of academic freedom, autonomy and purpose are weakened. She believes that this creates uncertainty regarding the roles of academics. Current focus on performance evaluations also affects the university's role as a free and critical voice (Lynch 2006). The increase in evaluations is said to affect the self-image of academia, leading to:

a type of Orwellian surveillance of one's everyday work by the university institution that is paralleled in one's personal life with a reflexive surveillance of the self. (Lynch 2006, p. 7)

Taylor (2001) argues that the increased focus on peer review in the social sciences and the humanities is another factor liable to limit the academic voice. When academics are 
primarily evaluated and rewarded for communication with each other through peerreviewed publications, incentives are lost for other forms of communication, such as public lectures, dialogue, or the media. This, we believe, is an expression of the paradoxical field of tension in which higher education is situated today. On the one hand, you are required to communicate and collaborate with society and industry; on the other hand, the organisation has been influenced by business ideals to a point where researchers are above all rewarded for publications addressing other researchers. This brings us to the second discourse which we propose to discuss in this article: academisation.

\section{Academisation}

Academisation is another trend witnessed in higher education today, but which has received comparatively little attention (Hazelkorn \& Moynihan 2010). Academisation can be viewed in the light of changes many vocational programmes have undergone, from being an alternative to university studies, to becoming an integral part of higher education. Fransson (2009) believes a fundamental conflict was created in Sweden between standards relating to the practice of the professions, and the university's critical traditions. This conflict was a consequence of the decision in 1977 to include all post-secondary education into the system of higher education. The ensuing diversification means that it is not possible to talk about the academic profession as a single type of activity, with shared experiences (Marginson 2000).

Academisation and demands for stronger links between research and teaching have compelled vocational programmes to change focus towards a more active involvement in research. Furthermore, these trends have had a tangible impact on the composition of staff in the individual departments, because the demand for doctoral degrees has increased (Hazelkorn \& Moynihan 2010). Within the vocational programmes, many teachers were originally employed with the primary task of teaching with a focus on professional practice. Several did not hold doctoral degrees, but instead benefited from a solid professional experience. One consequence is that scientific expertise has been lacking among the staff, to produce research results needed not only in order to compete for external research funding, but also to represent research-related education. Frequently, young researchers are recruited to increase the proportion of PhDs, which may lead to a conflict of interests. Teacher education can be seen as an example of the academisation of vocational training programmes. Clifford and Guthrie (1988) have pointed to the risk that a gap to the profession may be created when teacher training programmes adapt to the standards of the traditional university.

Nursing training is another type of vocational education in Sweden that has worked to gain academic status and develop a distinct scientific field of research. Fransson (2009) suggests that in this instance, the qualification has obtained increased autonomy through the balance that exists between the profession and the adjustments which have been made to meet academic requirements. Deans et al (2003) put forward the inherent difficulties in 
establishing nursing as an academic discipline, most notably concerning the status of nursing training relative to other academics, resources, workload and unclear roles. Teachers on the programme experience that the practical knowledge they impart is less valued and stands in contrast to the more theoretical knowledge which characterises traditional university disciplines. Also, teaching skills do not have the same high rank as conference presentations or the publication of articles (Barton 1998).

\section{Institutional cultures}

Many studies of scientific settings have shown how both disciplines and individual departments tend to develop distinct cultures, which involve shared norms and values, but also shared practices. Knorr Cetina (2003) writes:

/.../ those amalgams of arrangements and mechanisms - bonded through affinity, necessity, and historical coincidence - which, in a given field, make up how we know what we know. (Knorr Cetina 2003, p. 1)

Both Knorr Cetina and Välimaa (2008) point to the importance of analysing the relationships between ideas, as well as between individuals in the academic world, "with the theoretical assumption that academic communities are both epistemological and social communities" (Välimaa 2008, p. 13). This has significance in new interdisciplinary settings, with no clear disciplinary affiliations or academic traditions. Previous studies suggest both problems and opportunities in meetings between different disciplines, traditions and academic identities. Kezar and Eckel (2002) have shown that the changes do violence to the cultural norms that have hitherto dominated the organisation. However, such problems can be countered by employing "culturally sensitive strategies" (p. 436).

To understand conflicts between different demands that may be placed on an institution, we have chosen to interview prefects, coming from a range of institutional cultures. The task of prefect is to function as an intermediary, between the staff and the central university administration, as well as towards the National Agency. Their role is not entirely obvious, however, when it comes to leading activities. Within higher education, traditionally two main types of academic leadership have coexisted: administrative and scientific, that is, prefects (and deans) or professors, respectively. Occasionally, scientific and administrative leadership "collide".

\section{Method}

The study aims to describe and discuss how some changes in fundamental conditions governing higher education are expressed and dealt with at the level of prefects. More specifically, the study concerns ways in which tensions between marketisation and academisation are handled by prefects form various institutional cultures. To understand this, we interviewed 16 prefects at a Swedish university. We believe that the position prefects occupy makes it possible to clarify important issues. Their mission is to enforce centrally decided decrees and changes, in a "lean" organisation with dwindling staff and 
economic resources, but which is at the same time required to welcome student groups that are both larger and more heterogeneous. Squeezed between demands from above and below, we believe that the way prefects describe their activity can serve as a litmus paper, indicating how different institutional cultures respond to the changes outlined at the outset.

\section{Data collection}

The prefects who were interviewed represent about half of all the university's departments, and the group includes representatives from all faculties. Some of the prefects have only recently come to occupy this position, while others have held it for many years. Seven of the interviewees are men, nine are women. All but one hold a doctoral degree. The interviews were conducted by the four authors of the present article. They lasted for 1-1 $1 / 2$ hours and were all based on the same interview guide. The interviews touched a number of themes, including the department's staff composition (and status), the relationship between education and research, students, recruitment, different teachers and teaching styles, interdisciplinary settings, the manner in which policy reforms and other changes were handled, the university's policy. All interviews were recorded and transcribed. Individual participants have been anonymised and the abbreviations $P$ for Prefect and I for Interviewer have been used in the transcripts. However, the interviews have been given numbers, so that the reader can see the connection between the quotes.

Customary ethical standards have been followed. The prefects who were interviewed were informed about the nature of the study nature and have given their consent. An ethical dilemma, however, has been how to completely anonymise informants. Therefore we have chosen not to analyse them as individuals, but rather as a kind of ideal types, who express norms and values typical for their department.

\section{Method of analysis}

The first analytical step involved categorising the departments into two archetypes Discipline-oriented and Professional-oriented. The Discipline-oriented departments are characterised by meritocratic hierarchies and a theoretical orientation. Teaching has weak labour market focus, but strong focus on the academic disciplines, as such, and typically takes the form of lectures or literature seminars. The Professional-oriented departments are vocational training schools, with strong labour market focus. Instruction is characterised by theoretical and practical aspects, including practical training outside the school. In this kind of department, two types of hierarchies exist: on the one hand the academic meritocracy, and on the other, a hierarchy based on professional competence.

The second step in the analysis was to sift out key elements in the interview material and from the literature, which would allow us to compare the two different institutional archetypes. The first categories that were created in this process were academisation and marketisation. With academisation is here meant greater demands on linking teaching to research, requirements for teachers to hold research qualifications, and a quality assurance system that focuses on students' scientific work (rather than, for instance, practical training 
periods). The notion of marketisation refers to demands for increased interaction with society at large, clear employability after training, as well as demands for efficiency in training.

The third step in the analysis is to understand the talk about academisation and marketisation, seen from the institutional contexts of the prefects. Ways in which the talk reflects the context at different levels are analysed, both with respect to the local practice at the university and broader societal discourses on higher education. As regards the different levels, we believe that the statements of the prefects should be understood as effects of a specific local practice. This is here a question of analysing their narratives in relation to the archetypal institutional culture. In addition, we wish to relate the stories of the prefects to broader ideals concerning higher education, such as the role higher education plays in society, what type of knowledge is most relevant for the various programs, what kinds of activities should teachers engage in. It's also a question of how the reforms and policy decisions at a national level are filtered through local practices.

\section{Results}

The analysis of the interviews makes it clear that Swedish higher education lies in a field of tension, where requirements of maintaining a high academic level are formulated, at the same time that training is expected to be "useful", that is, useful to society outside the academic world. The interview quotation below illustrates this tension.

P: One of the most important things too, which is also one of the challenges, is to maintain a relatively high academic level, at the same time that it is something which can be useful and applicable. Well, that is what we are right in the middle of. (1)

In the presentation of results below, we will show that the tensions between academisation and marketisation, expressed by this prefect, appear in different ways depending on the institutional culture. The sequence of this section is organised to show how the discourses are expressed in the context of the two institutional archetypes: Discipline-oriented and Professional-oriented. The analysis outlines how discourses on "the new academy" are filtered through the department's everyday practice and how they are expressed by the prefects.

\section{Marketisation}

New Public Management is a recurrent theme in the stories about "the new academy". It is about clear employability after graduation, but also concerns market adjustment of the education as such. The section begins by providing a picture of how the prefects from the Discipline-oriented departments reason about this theme. This is then contrasted to how prefects at the Professional-oriented departments handle the issue. 


\section{The Discipline-oriented Cultures}

P: Well, one need not be a weathervane in following policy, but you do have to face realities. (2)

In the Discipline-oriented institutional culture, we encounter the same criticism of the "new" marketified academy which dominates critical research (e.g. Ball 2004). The problem with increased control is a recurrent theme. The prefect, who here comments that he does not want to become a political "weathervane", thereby indicates a criticism of rapid changes that have been decided without scientific basis. The Bologna reform, with ensuing demands for management by objectives and employability, drives changes that challenge the traditional humanist ideals of Humboldt.

P: It feels like when we started this department and in our educational culture a fairly high academic culture - there was a certain scepticism towards strengthening management by objectives. With some justification. A fair amount of research is conducted around the issue of management by objectives as well, and I feel that there may be an instrumental management approach involved that does not promote learning processes. It could be a threat to academic knowledge. (3)

According to the prefects, academic knowledge and skills can not always be captured in the model of management by objectives. Instead, institutional educational aims may involve a classical educational ideal or the competence to conduct an academic conversation. The marketisation of higher education is almost described as a threat to the department's own educational culture. A concrete expression of this was when it had been decided to rebuild the seminar room and remove the lunchroom in one of the areas belonging to the department.

P: I said it would be like removing the living room and kitchen in a family. /---/ So that one might say it is a culture of academic seminars. (3)

The tensions are also manifested in how prefects talk about careers and employability after graduation. One way to handle the requirement of employability was to introduce so-called labour market days.

In this manner, teachers at Discipline-oriented departments could be liberated from any responsibility concerning employability. They were able to maintain a discourse about themselves in terms of continuing to be traditional academics, while the students were offered links to professional life. In the next section, we shall present the stories of the Professional-oriented departments concerning the marketisation of the university, which differs on several points from the picture outlined above. 


\section{The Professional-oriented Cultures}

Several of the prefects from the vocational training programmes are in charge of schools preparing students for professions that require certification, or occupations with strong professional traditions. The courses have traditionally had strong links with future employers, and both campus courses and practical training periods are the subject of examinations. This places special demands for "market adjustment" in terms of the quality of practical training placements, but also a need to meet the changes and demands of the professions. With respect to health science courses, future employers' demand for practical skills is noticeable:

$P$ : And then we have clinical training too, because the [students] have to know certain things when they come out. /---/ it feels quite good to know how to take blood pressure and how to calculate this or that. That you bring these technical elements with you, because all those other things about how to behave in contacts [with patients], which are really the hardest, these will of course have to come as you go along. (4)

Some difficulties are experienced with respect to the meeting between the programme and "the labour market". Even here you can talk about different traditions and habits that clash, not least in terms of views on what constitutes knowledge.

P: I think many students have heard that "Now am I doing this, but you mustn't do it, because you are not actually allowed to do it that way. So you should not learn it." What kind of pedagogy is that? (4)

The programs which do not involve longer training periods, but which are still oriented towards a clear set of professions after graduation, solve the issue of links to working life in other ways. For instance, they may invite representatives of the market to participate in training in various ways, industry can be asked to take care of parts of courses, or students may write their degree projects in collaboration with companies:

I: Is having one foot in practice an important part of teachers, you need to be familiar with practice?

P: /---/ everybody doesn't need to have done that. But that you still have a partnership with practice. In different ways, it may be their degree theses, it may be that representatives from various industries come in and give lectures, and so on. I think that is important. (1)

One of the prefects speaks about his own department as "an established brand". Within that institutional culture, the marketisation of higher education is seen as a good thing. The market does not exist outside, but rather within the education itself. The prefect lists a number of ongoing so-called "sharp projects" in collaboration with large companies and institutions. 
P: I often say that we're partly an academic institution, and partly a cultural institution in the region. Because a tremendous amount of production takes place here: by students and teachers and in collaboration with others. Much more - I think actually - than more established cultural institutions might produce. (5)

Here, management has taken on a different meaning than in the Discipline-oriented institutional cultures. It is built into the system. Another prefect also speaks of his research base in the programme as part of an established "brand":

$P:$ It is above all the question of strengthening the ties between research and the first cycle of studies, and if we succeed in this, then I think that we also become more attractive to others, for collaboration with other research stakeholders. And this could mean other universities, but also industry and the society, funding agencies and the like. (6)

In the Professional-oriented department, no one talks about the problems of adapting education to the labour market or in making students employable. Such issues have been part of everyday life for a long time, which is also reflected in the staff composition. Many of these prefects talk about the need to employ both staff with professional expertise and scientifically competent teachers. The need to have teachers with different types of qualification is often spoken of in terms of lecturers and senior lecturers - these two categories are symbols for teachers with different status in higher education - but also partly different tasks. A prefect speaks of the lecturers as the mainstay of the programme:

P: They will often be wholeheartedly committed to the programme in some sense, and of course, from their professional expertise they - well both professional experience but also ... they simply know how to teach about a subject. And constitute a good example. (8)

The same prefect also describes the work of the teachers who hold a doctoral degree:

P: But on the other hand, I do feel that the senior lecturers can easily become more fragmented in their work. Often they additionally have to stand on the leg of academic qualification. (8)

The last two quotations leads us to the discourse which the Professional-oriented institutional cultures perceive as far more problematic than the marketisation of higher education, namely academisation. In the talk about lecturers versus senior lecturers, and teachers who hold a PhD or not, traces of the traditional academic hierarchical meritocracy can be found. This academic system of values is difficult to transfer to the vocational training programmes, in which hierarchies based on professional expertise compete with the meritocratic hierarchies 


\section{Academisation}

A clear intention has been expressed by the Swedish government to "academise" the vocational training programmes. Demands are made to relate teaching to research, which is reflected in the National Agency's evaluations of programmes, as well as in the Agency's considerations when conferring the right to issue qualifications. In the following section, we will show how the prefects talk about their departments in relation to academisation.

\section{The Professional-oriented Cultures}

P: On our programme, of course the teachers come from $Y$ and $Z$ [other programmes], which were very professionally oriented. And those were programmes with a practical approach. So that the teachers who are left, well they carry the traditions with them. /---/ And then academisation came into the picture. Some do have a little of both, and others only have one of these [i.e., either research qualifications or professional experience]. But at the end of the day, I think that most combine.

\section{I: But is this academisation you are talking about a problem?}

P: I belong to those who think you can balance this. And there really is no contradiction between theory and practice. Instead, it should be possible to combine them. But I can see that it is not that way for everyone. And that it becomes a problem if academisation takes the upper hand. It is one of these points, with the National Agency, not towards us but towards some others, because one feels that academisation has received too much space. It should be there, one does want it. But it must not be at the expense of profession-specific considerations. (9)

If marketisation is seen as an obvious aspect of the vocational training programmes, demands for increased "scientificity" are a vexation for the prefects. Among other things, the requirement of academisation takes the form of demands that the number of teachers holding a PhD be increased - which, in turn, has had the tangible effect of lecturers being dismissed and senior lecturers recruited

P: In its evaluations, the National Agency has stressed that you have to raise the proportion of teachers with a PhD. And that's one of the things that has started this adjustment process, both with layoffs and changes in resources ... and new recruitment. It is also important to say that almost all new teachers recruited today have PhDs. This is during a transitional period, as I see it, because the programme must have a balance. (10)

In the two quotations above, the tension between "scientificity" and professional experience is clear. The prefects attempt a balancing act, which is manifested discursively through expressions like "I belong to those who believe that they can balance this" and "This is during a transitional period, as I see it, because the programme must have a balance." They are 
right in the middle of the field of tension, where they have to deal with staff and traditions, while also addressing the demands imposed through decrees from above. Tensions within the departments have been significant; the layoffs of staff without PhDs has led to conflicts and reduced the sense of belonging. At the same time, it is extremely difficult to recruit teachers with research qualifications to vocational training programmes - there is simply a lack of qualified teachers. The demand exceeds the supply. Among other things, this leads to recruiting staff with disciplinary qualifications that would not normally match the programme. Several of the prefects talk about problems in recruiting senior lecturers with the "right profile":

P: The main point is that they hold a PhD degree. That's the way it has to be now. /---/ And many of them have written their dissertations in areas that have no connection whatsoever with school, or didactics and pedagogy and things like that. (11)

P: We have hired many from other disciplines. When we had to academise the department, the university made the choice of a very wide recruitment from the social sciences. So there are not that many who hold doctoral degrees in the discipline itself. (9)

Recruitment is "wide". Another of the prefects warns against "throwing out the baby with the bathwater." The problem of finding the right "kind" of senior lecturers is difficult to resolve in practice, when you are under the close scrutiny of the National Agency. The prefect says also that one has to adapt to the requirements to get "graduation rights".

The Discipline-oriented departments reflect their scientific identity in the large neighbouring university. In contrast, the vocational training programmes use significantly less of a "University repertoire" when discussing scientificity. For these departments, the National Agency's requirement becomes the yardstick of "scientificity". Scientificity and academisation thereby - paradoxically - amount to what can be described within the framework of evaluation matrices in a developed quality assurance system.

In other words, academisation as a problem for the organisation is a recurrent theme in the talk about the vocational training programmes. In the following section, we shall change the setting, and once again hear a different story about academisation.

\section{The Discipline-oriented Cultures}

P: Someone has called us "little X" [i.e., the large neighbouring university]. You could say that we carry our tails fairly high academically. We do not feel that "academic" is a bad thing; instead, it is a positively charged word. But it's about being aware and having a culture of seminars, having theories, and so forth. (3)

The academic approach, and safeguarding traditional ideals of higher education and research, is reflected in everything, from views on "the seminar room", to how to behave 
within it and what education and research look like. The staff consists mainly of senior lecturers holding PhD degrees and who have clear research focus. Teaching has low status, at least as long as you do not have the opportunity to teach about "your own" topic - and then in a much narrower sense than when one of the prefects above mentioned "school, or didactics and pedagogy, and things like that". The senior lecturers have homogenous views on research and teaching, which means that interdisciplinarity does not give rise to a pronounced tension.

Conflicts between senior lecturers and lecturers are not expressed in the talk of the Discipline-oriented institutions. Nor are problems with the National Agency's assessment of "scientificity" mentioned, whether in respect to teaching or students' degree theses. These departments have no problems with recruitment - on the contrary, there are plenty of unemployed humanists and social scientists. The institutional culture can be placed in a different position in the field of tension between academisation and marketisation. The discourse on academisation is in the traditional disciplinary courses not a challenging issue, because these departments and programmes are themselves key players in it. Students are socialised into a research culture - just as students on the vocational training programmes are socialised into professional cultures. In other words, quite different institutional cultures, with different kinds of tensions, coexist within the same university.

\section{Analysis}

Based on these results, we wish to point to the importance of understanding how reforms and demands for changes in higher education are handled within the local institutional cultures. Disregarding more specific cultural particularities, differences appear between the archetypes Discipline-oriented and Professional-oriented. The most common discourse in in research is that "the new academy's" requirements for market adjustment threaten the hallmark of higher education. We wish to argue that this is not general to all higher education. In vocational training programmes, with a large proportion of practical training periods and frequent contact with the profession, marketisation is perceived as a limited problem. These institutional cultures have long contributed to knowledge production which reaches beyond their own department. Knowledge is simply supposed to be useful.

Tensions within the Professional-oriented cultures primarily concern the fact that the link to the "market" is challenged by demands for academisation. Prefects are talking about how they try to balance between demands from stakeholders, on the one hand, and the requirements of the National Agency, on the other. This has had consequences in terms of dismissals of lecturers without research qualifications, and appointments of senior lecturers with PhD degrees. In addition to the psycho-social problems that normally arise in periods when staff are dismissed, these changes in staff composition have had an impact on the view of what constitutes knowledge.

Theoretical knowledge and a scientific approach have gained more room, at the expense of training in practical skills. Lecturers are losing status and are excluded on structural grounds, 
even if one of the prefects states that the present policy of only recruiting staff with PhD qualifications is just a transitional phase. The observed changes are also consistent with Fransson's (2009) analysis of the conflict created when the practical training programmes were incorporated into the higher education system, and measured by the same standards as traditional university programmes. When prefects talk about "not throwing out the baby with the bathwater", or sigh over the newly employed senior lecturers who do not have any research relation to the core aims of the programme, they also embody the fundamental conflict between professional standards and the university's critical traditions.

The increased importance of the peer-review system is another factor which affects the relationship between vocational training programmes and the labour market. Taylor (2001) argues that among the consequences of the peer review system is that scientists prefer to communicate with other scientists, rather than with users and the public. Several of the prefects of the Professional-oriented cultures feel it is problematic that the senior lecturers are primarily focused on research, and less interested in the first cycle of training.

Besides the fact that academisationen is reflected in shifts in staff composition and changes in the links to research, it has involved adjusting to research settings with a more interdisciplinary character. Prefects have been "forced" to recruit skilled scientific personnel from a number of disciplinary areas, since strong traditions or incentives are lacking for professional groups, such as nurses, social workers and teachers, to obtain qualifications at third cycle levels. Interdisciplinarity creates tensions in the local institutional culture, where norms and traditions are challenged by new perspectives and differing knowledge traditions. Hierarchies change and knowledge visions are challenged. Knorr Cetina (2003) concludes that this may have an impact on how new knowledge and new norms are constructed. In this type of institutional culture, both Reich and Reich (2006), and Kezar and Eckel (2002) point out, you may have to find new "culturally empathetic" ways to create opportunities, rather than problems in multidisciplinary encounters, even when they have not been freely chosen. A constructive, open-minded approach is essential, not least in times of change and when hierarchies are challenged.

The Discipline-oriented programmes have a strong identity in the institutional cultures and scientific views of the humanities or the social sciences, respectively. They refer to an established institution in the form of a prestigious university, and thereby gain academic credibility. The right to apply their preferred epistemological interpretation is not threatened in the same way from within the organisation. This academic self-confidence spills over to some extent on their perception of marketisation, as well - which for them signifies to incorporate fragments of career considerations in education. This strategy may not have much significance for the composition of staff; the problem is resolved through actors outside the local practice. Within the department, teachers are not forced to negotiate in the same way about what constitutes valid knowledge, or what confers status. 
On the other hand, restrictions in the economic framework (student allowance, research grants, etc.) have weakened the institutions. Just as they speak of solutions to the issue of market adjustment as lying outside their own department, prefects also refer to financial constraints as something existing outside their own scope of action. However, Benner and Sandström (2000) argue that Discipline-oriented departments also need to adapt to demands from the market and politicians. In either case, autonomy has been weakened for the Discipline-oriented programmes as well, but the change occurs through reduced financial resources, rather than mediated by the threat of losing the right to issue qualifications. But, as Lynch (2006) puts it, in both cases there is a kind of "Orwellian" surveillance, which requires increased reflexivity on the part of both prefects and teachers, in order to find a suitable position within the new academy's fields of tension.

\section{Discussion}

What clearly emerges from this study is that it is problematic to talk about changes in the new academy, as if we assume that conditions do not differ substantially across the university. In the discourse on "the new academy" in research, discussions mainly concern the problem of market adjustment. We see this as a result of the fact that traditional courses given at large universities are frequently used as examples.

Our intention has been to broaden the debate, both by focusing on vocational training programmes at a university, and by exploring how changes are handled at the micro level. We can thereby show that the talk about change in higher education needs to be differentiated, since different types of education are faced with different challenges in the process of change. These challenges are linked to the aims of the education, but also to prevailing traditions, academic affiliation and composition of staff. The strong research focus placed on problems linked to marketisation must be extended, to also study the problems which arise when vocational programmes are academised, increasing demands are placed on "scientificity" and less attention is devoted to skill and practical experience. What do the reforms and decrees involve for different courses, considering their various aims and functions? How can change be implemented in a more "culturally empathetic" way?

In line with Kezar and Eckel (2002), we believe it is necessary to place oneself outside, on "the balcony", to be "able to look down on the dance floor" (p. 457) where the changes are to be implemented, since institutional cultures vary, and require different strategies. This study also shows that particular cultural empathy is needed to work in interdisciplinary settings. Various research and teaching traditions meet, involving distinct views on knowledge, as well as varying expectations on how education should be implemented, and with what goals. The emergence of interdisciplinary cultures is often characterised by the dissolution of existing hierarchies. The process of dissolution creates tensions, and a struggle for precedence of interpretation and status occurs. One of the tensions which arises it the clash between academisation and marketisation, partly resulting from the fact that decrees 
"from above" are not compatible with the ideals that prevail on vocational training programmes.

On the other hand, one could reflect on whether academisation and marketisation really constitute opposites. We can see that these two, seemingly opposed discourses are sometimes expressed in the same practice. The peer review system is one such example; it is based on competition and the allocation of financial resources based on performance. At the same time, it is a powerful symbol that ensures that academic rules are upheld. Another practice where discourses meet, are the demands for evidence-based practice in areas such as education and care. This is an instance where the ideals of science have been transferred to the market. Can it be that these two discourses in fact are two sides of the same coin - the politicisation and tighter governance of higher education - while in the talk of change they are frequently presented as opposed to each other? The fact that a government agency, the Swedish National Agency for Higher Education, has become the touchstone of "scientificity" for vocational programmes is, we believe, a significant indication in this respect.

\section{References}

Ball, S.J (2004) Education For Sale! The Marketisation of Everything? King's Annual Education Lecture, University of London, June 17, 2004. Retrieved from http://sys.glotta.ntua.gr/Dialogos/Politics/CERU-0410-253-OWI.pdf 25-05-2011

Barton, T.D. (1998) The integration of nursing and midwifery education within higher education: implications for teachers - a qualitative research study. Journal of Advanced Nursing, 27: 1278-1286.

Benner, M., \& Sandström, U. (2000) Institutionalizing the triple helix: research funding and norms in the academic system. Research Policy, 29(2) pp 291-301.

Clifford, G. J. \& Guthrie,J . W. (1988) Ed School: a brief for professional education, Chicago, IL, University of Chicago Press

Deans, C, Congdon, G, Sellers, E. T. (2003) Nurse Education in English Universities in a Period of Change: Expectations of Nurse Academics for the Year 2008, Nurse Education Today, 23: 146-154.

Fairclough, N (1992) Discourse and social change. Cambridge: Polity Press.

Fransson, A. (2002). Ledarutveckling - ett styrinstrument? Insatser för chefs- och ledarutveckling vid universitet och högskolor 2000-2001. Stockholm: Högskoleverkets rapportserie 2002:19R

Fransson, O (2009) Epistemisk förskjutning och autonomi. I O. Fransson \& K Jonnergård (Eds) Kunskapsbehov och nya kompetenser. Professioner i förhandling. Stockholm: Santérus förlag. 
Harris, S. (2005) Rethinking academic identities in neo-liberal times. Teaching in Higher Education. Vol 10 (4) pp 421 - 433.

Hazelkorn, E and Moynihan, A (2010) The Challenges of Building Research in a Binary HE Culture. In: S. Kyvik and B. Lepori (eds) The Research Mission of Higher Education Institutes outside the University Sector. Dordrecht: Springer.

Kezar, A \& Eckel P.D. (2002) The Effect of Institutional Culture on Change Strategies in Higher Education: Universal Principles or Culturally Responsive Concepts? The Journal of Higher Education 73.4 pp 435-460

Knorr Cetina, K (2003) Epistemic cultures. How the sciences make knowledge. Cambridge, MA: Harvard University Press.

Kolsaker, A (2008) Academic professionalism in the managerialist era: a study of English universities. Studies in Higher Education, vol 33 (5), pp 513-525.

Lynch, K (2006) Neo-liberalism and Marketisation: the implications for higher education. European Educational Research Journal, Vol 5(1) pp 1-17.

Marginson, S. (2000). Rethinking Academic Work in the Global Era. Journal of Higher Education Policy \& Management, 22(1), pp 23-35

Olssen, M. (2002) The neo-liberal appropriation of tertiary education policy in New Zealand: Accountability, research and academic freedom. State-of-the-Art Monograph no. 8, New Zealand: Association for Research in Education, Wellington.

Reich, S M \& Reich, J A (2006) Cultural Competence in Interdisciplinary Collaborations: A Method for Respecting Diversity in Research Partnerships. Am J Community Psychol (2006) 38:51-62.

Taylor, J. (2001) The impact of performance indicators on the work of university academics: evidence from Australian universities. Higher education quarterly 55:1 , no 4, pp. 421-433.

Välimaa, J (2008) Cultural studies in higher education research. I J Välimaa \& O-H Yljokki (eds) Cultural Perspectives on Higher Education , s 9-25, Dordrecht: Springer Science. 